\title{
Diagnostic yield of analysis of the pattern of electrical activity and of individual motor unit potentials in myopathy
}

\author{
A. FUGLSANG-FREDERIKSEN, U. SCHEEL, AND F. BUCHTHAL \\ From the Laboratory of Clinical Neurophysiology, University Hospital (Rigshospital), \\ and the Institute of Neurophysiology, University of Copenhagen, Denmark
}

SYNOPSIS The analysis of the pattern of electrical activity and of individual motor unit potentials in the same muscle both identified about $90 \%$ of 41 patients as having a myopathy. The pattern of electrical activity was analysed during a force which was a fixed fraction of maximum; individual motor unit potentials were analysed during weak effort. The two methods supplement each other as some of the patients were identified only by one or by the other of the two procedures. The parameter of the pattern of electrical activity which was most often abnormal was the ratio: numbers of turns to mean amplitude between turns.

The pattern of muscular electrical activity recruited during full effort in myopathy is in most instances similar to that of normal muscle, but on closer inspection the individual spike potentials are shorter in duration and come with shorter time intervals. Willison has measured this change by counting the number of spikes (turns) and their amplitude, at a given effort (Willison, 1964; Rose and Willison, 1967). The appearance of an increased number of spikes is to be expected from the shortened duration of motor unit potentials. When a weak muscle exerts the same standard force $(2 \mathrm{~kg})$ as a normal muscle the high incidence of spikes per unit time may be due to the activitation of more motor units and to an increase in their firing rates or to more specific changes in individual motor unit potentials. To distinguish between these possibilities we measured the pattern of activity at a force which was a fixed fraction of the maximum force of the muscle (Fuglsang-Frederiksen and Månsson, 1975). We then compared the diagnostic yield obtained by measurements of the recruitment pattern with that obtained by measurements of

(Accepted 30 March 1976.) duration, amplitude, and shape of motor unit potentials recruited in the same muscle during weak effort.

\section{METHODS}

PATIENTS A total of 41 patients with myopathy were examined. Of these 26 had progressive muscular dystrophy (15 of facioscapulohumeral type, 10 of limb-girdle type, one of benign Becker type), four patients had congenital myopathy, eight had myotonic dystrophy, and three had polymyositis. Only those patients were included in whom the diagnosis was established by history, clinical findings, enzyme studies, histopathology, and histochemistry (Table 1).

PROCEDURE 1. Muscles examined Elbow flexors ( $\mathrm{m}$. biceps brachii and $\mathrm{m}$. brachialis) were studied in all patients. M. triceps brachii was studied in 10 patients. Thirty-three of 41 patients had a diminished force in elbow flexors and four of 10 patients had a diminished force in the brachial triceps muscle (Fig. 1).

2. Analysis of individual motor unit potentials The recording electrodes and the amplifiers used have been described by Fuglsang-Frederiksen and Månsson (1975). The platinum core of the concentric needle electrode (DISA $13 \mathrm{~K} \mathrm{32}$, external diameter 
TABLE 1

CLINICAL AND LABORATORY FINDINGS IN 41 PATIENTS WITH MYOPATHY

\begin{tabular}{|c|c|c|c|c|c|c|}
\hline & \multicolumn{6}{|c|}{ Type of myopathy } \\
\hline & $A$ & $B$ & $C$ & $D$ & $E$ & $F$ \\
\hline Number of patients & 15 & 10 & 1 & 4 & 8 & 3 \\
\hline Sex (male/female) & $8 / 7$ & $8 / 2$ & $1 / 0$ & $1 / 3$ & $2 / 6$ & $0 / 3$ \\
\hline Age (yr) & $23-64$ & $19-60$ & 17 & $18-59$ & $17-49$ & $28-55$ \\
\hline \multicolumn{7}{|l|}{ Age at onset (yr): } \\
\hline$<20$ & 8 & 4 & 1 & 2 & 4 & 0 \\
\hline \multicolumn{7}{|l|}{ Duration of disease $(\mathrm{yr})$ : } \\
\hline$<3$ & 3 & 1 & 0 & 1 & 4 & 3 \\
\hline $3-10$ & 5 & 6 & 1 & 0 & 1 & $\mathbf{0}$ \\
\hline$>10$ & 7 & 3 & 0 & 3 & 3 & 0 \\
\hline Positive family history & 6 & 2 & 1 & 0 & 8 & 0 \\
\hline \multicolumn{7}{|l|}{ Decreased force: } \\
\hline Facial muscles & 4 & 0 & 0 & 0 & 0 & 0 \\
\hline Flexor muscles of the head & 5 & 3 & $\mathbf{0}$ & 1 & 3 & 3 \\
\hline Head flexor and facial muscles & 3 & 1 & 0 & 0 & 5 & 0 \\
\hline \multicolumn{7}{|l|}{ Upper extremity: } \\
\hline Proximal muscles & 8 & 5 & 1 & 1 & 0 & 1 \\
\hline Distal muscles & 1 & 0 & 0 & 1 & 5 & 1 \\
\hline Proximal and distal muscles & 3 & 3 & 0 & 1 & 1 & 0 \\
\hline \multicolumn{7}{|l|}{ Lower extremity: } \\
\hline Proximal muscles & 2 & 6 & 1 & 1 & 0 & 0 \\
\hline Distal muscles & 5 & 1 & 0 & 0 & 2 & 0 \\
\hline Proximal and distal muscles & 8 & 2 & 0 & 0 & 3 & 2 \\
\hline \multicolumn{7}{|l|}{ Tendon jerks weak or absent: } \\
\hline Knee & 9 & 8 & 1 & 3 & 5 & 0 \\
\hline Heel & 10 & 5 & 1 & 3 & 5 & 1 \\
\hline Arms & 12 & 9 & 1 & 3 & 6 & 2 \\
\hline Tendon jerks normal & 1 & 0 & 0 & 1 & 2 & 1 \\
\hline Creatine kinase increased & 9 & 9 & 1 & 2 & $5 / 7$ & 2 \\
\hline Biopsy: compatible with myopathy & $13 / 13$ & $8 / 8$ & $1 / 1$ & $4 / 4$ & $7 / 7$ & $2 / 3$ \\
\hline
\end{tabular}

A : facioscapulohumeral. B: limb-girdle. C: Becker. D: congenital. E: myotonic dystrophy F: polymyositis.

of the cannula $0.65 \mathrm{~mm}$ ) had a leading-off area of $0.07 \mathrm{~mm}^{2}$ and an impedance of $400 \mathrm{k} \Omega / 20^{\circ}$ at $20 \mathrm{~Hz}$, $180 \mathrm{k} \Omega / 75^{\circ}$ at $50 \mathrm{~Hz}$ and $30 \mathrm{k} \Omega / 60^{\circ}$ at $500 \mathrm{~Hz}$. The total duration of motor unit potentials recorded during weak effort was measured at a gain of $0.1 \mathrm{mV} / \mathrm{cm}$, the peak-to-peak amplitude at a gain of 0.1 or $0.3 \mathrm{mV} / \mathrm{cm}$. At least 30 potentials from different motor units were sampled in each muscle from at least 18 different sites and a mean value was obtained for total duration of the motor unit potentials and peak-to-peak amplitude. In addition we determined the incidence of polyphasic potentials (more than four phases), the pattern of recruitment during full effort, and its amplitude measured between the envelope curves (Buchthal, 1957). Findings in patients were compared with those in controls matched for age (Table 2).

3. Pattern of recruitment during moderate effort Number of turns, mean amplitude, incidence of short time intervals and of small amplitudes between turns (Willison, 1964; Fitch, 1967; Dowling et al., 1968), and the ratio between turns and mean amplitude $^{1}$ were measured for five seconds of isometric effort at constant strength (Medelec APA 6). Ten sites were examined in each muscle, obtained by three insertions in proximal, middle, and distal parts of the muscle and by changing the depth of insertions in steps of at least $5 \mathrm{~mm}$. The criteria of abnormality are given in Table 2 .

4. Number of turns with different thresholds of voltage shifts Components of motor unit potentials in patients with myopathy often have a lower amplitude than controls. We have therefore compared the number of turns obtained with a threshold of voltage shift of $50 \mu \mathrm{V}$ with that of $100 \mu \mathrm{V}$. With decreasing threshold the percentage increase in turns at the same mean amplitude was the same in 15 patients as in six controls, irrespective of whether the number of turns per $5 \mathrm{~s}$ was increased (two patients), normal (six patients), or decreased (seven patients) (Fig. 2). Therefore a lower threshold of the voltage shifts did

${ }^{1}$ The diagnostic value of the ratio of turns to mean amplitude in young children was stressed by Smyth and Willison (1975). 


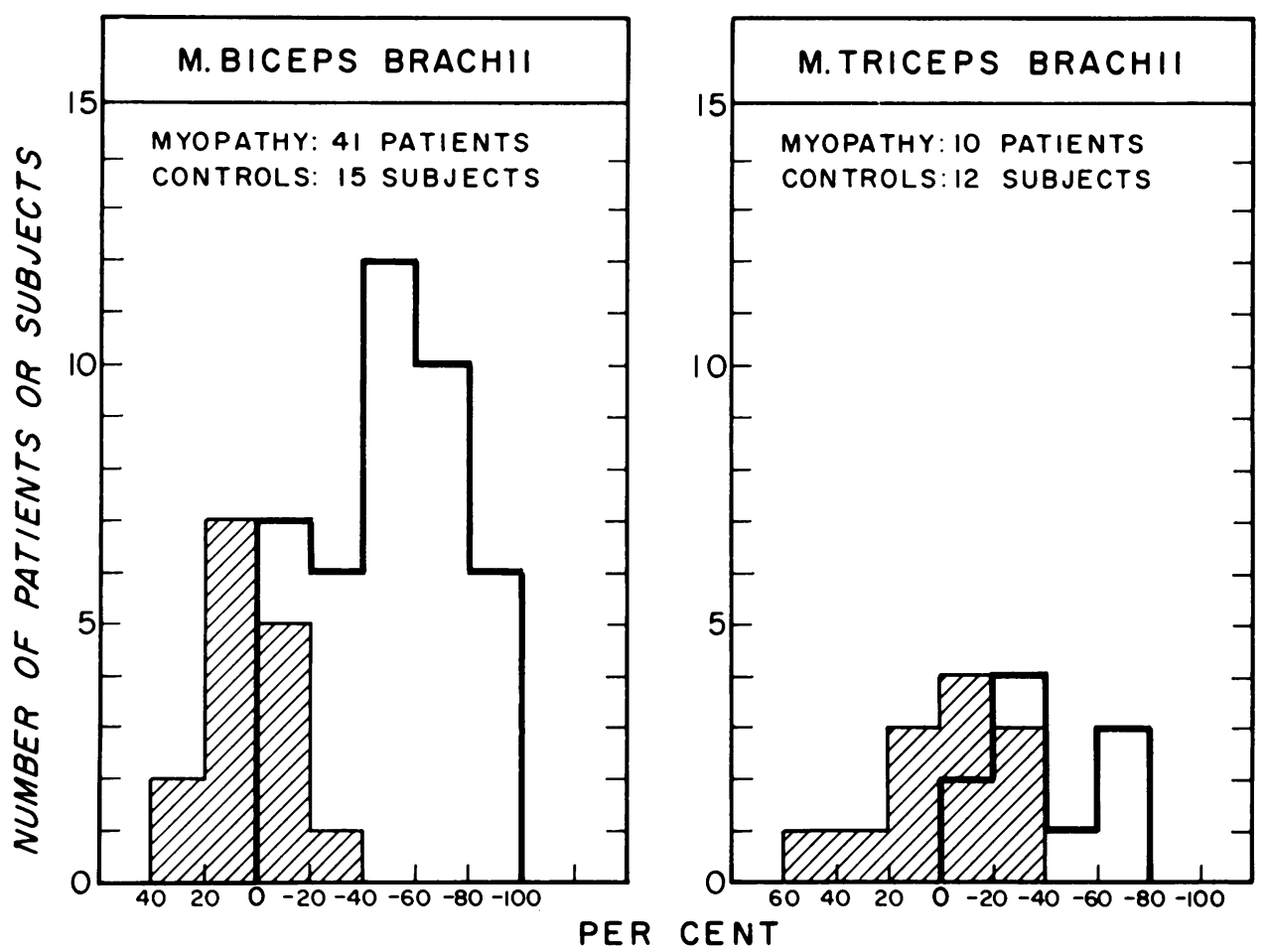

FIG. 1 Decrease in maximum force in myopathy (thick lines) in per cent of the average force of normal subjects $(0 \%)$. The striped columns indicate the range of force in controls.

TABLE 2

ELECTRICAL PARAMETERS INDICATING MYOPATHY (MEAN AND 95\% CONFIDENCE LIMITS)

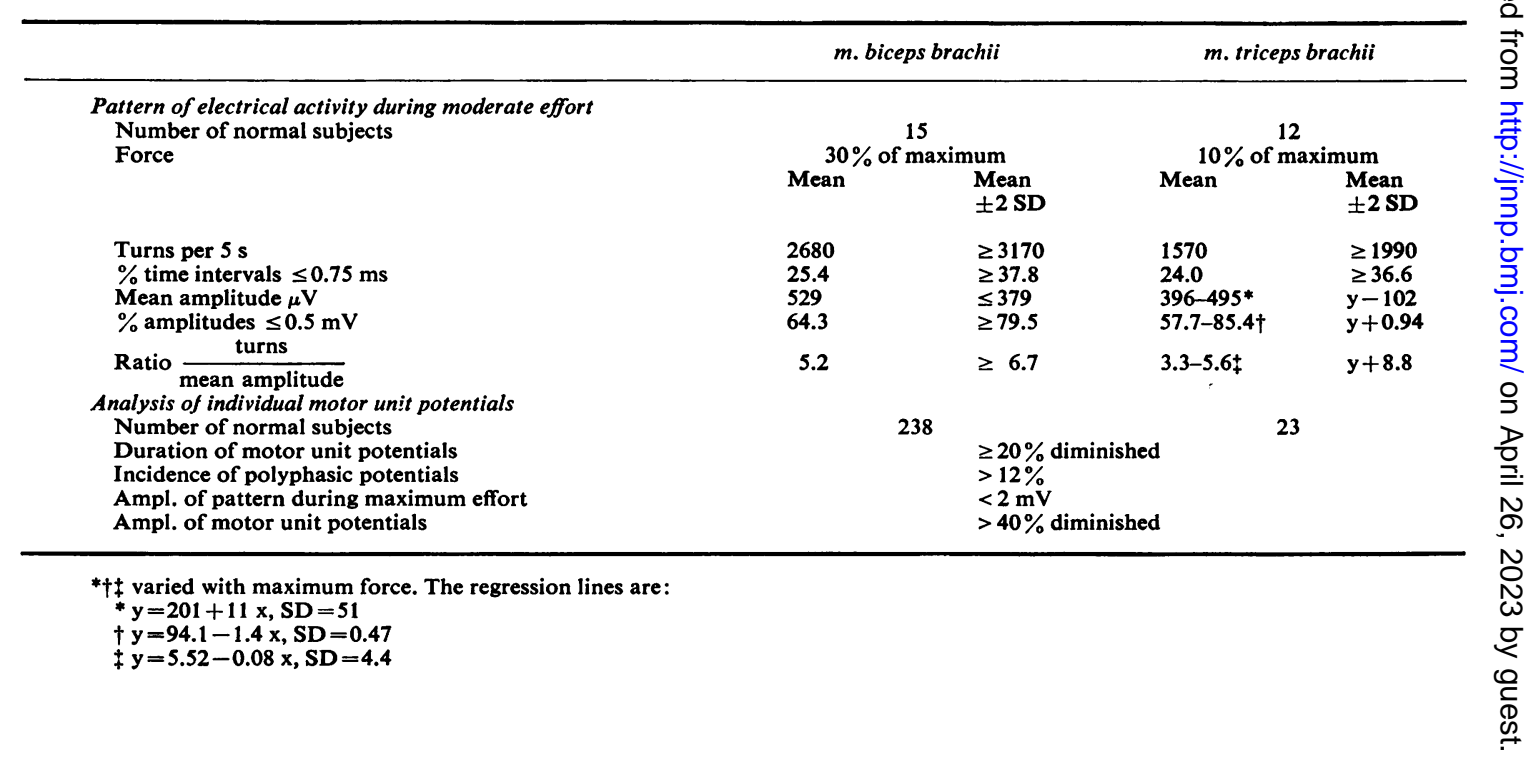




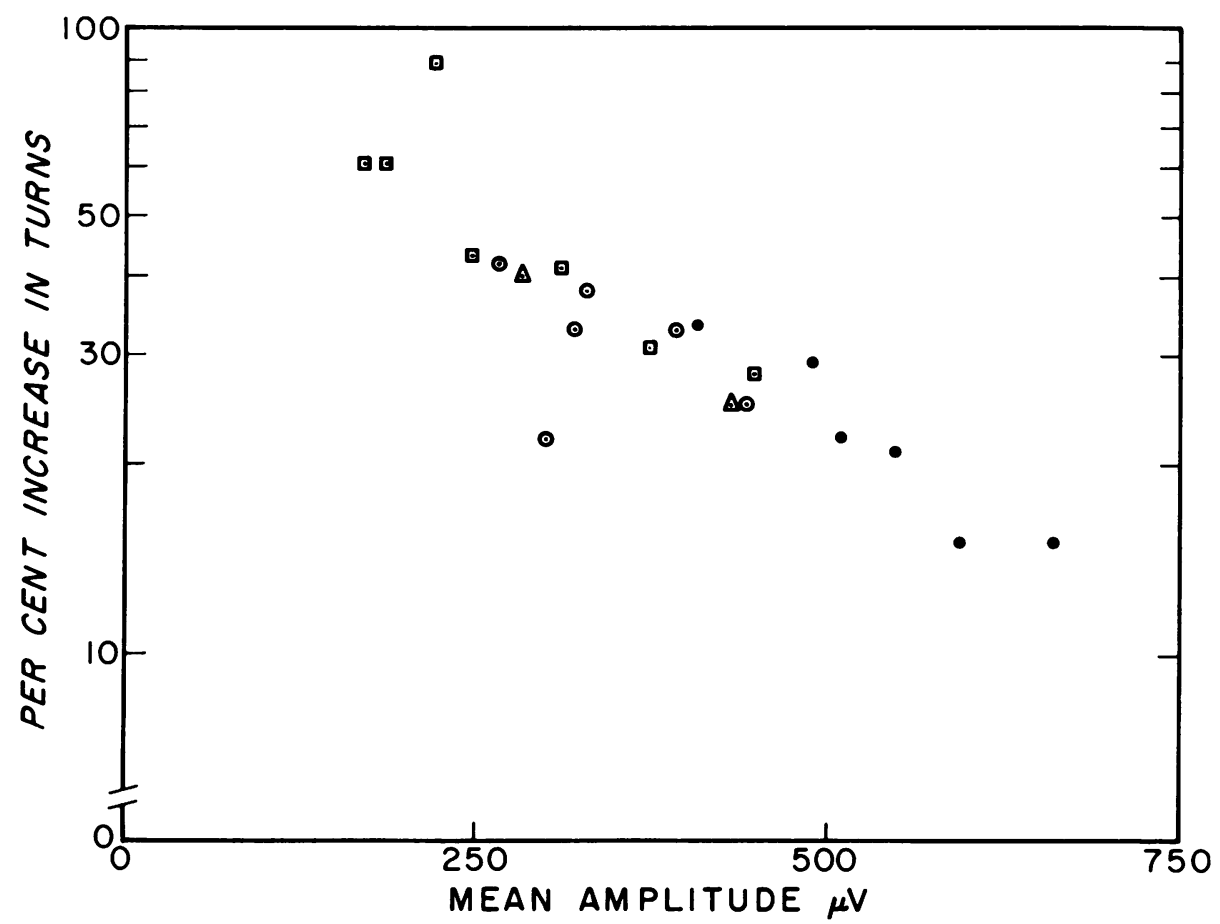

FIG. 2 Effect of a reduction of the threshold in voltage shifts ( $m$. biceps brachii). Ordinate: increase in the number of turns per $5 s$ when the threshold of voltage shifts was decreased from 100-50 $\mu V(\log$. scale). Abscissa: mean amplitude between voltage shifts at a threshold of $100 \mu \mathrm{V}$. Patients with myopathy, $\bigcirc:$ with normal number of turns, $\triangle:$ with increased number of turns, $\square$ : with decreased number of turns, $\bullet:$ six control subjects.

not increase the diagnostic yield in patients with myopathy.

\section{Wire electrodes compared with concentric electrodes} Wire electrodes cause less discomfort than concentric electrodes. We have therefore examined whether they could be used for measurement of activity. The wire was insulated and had a bared length of $10 \mathrm{~mm}$ $(0.08 \mathrm{~mm}$ in diameter). In control subjects the average number of turns with wire electrodes was the same as with concentric electrodes. However, the increased number of turns found with concentric electrodes in muscles of patients with myopathy was obscured when wire electrodes were used.

6. Measurement of force The force was recorded with the elbow joint at a right angle on a dynamometer as described (Fuglsang-Frederiksen and Månsson, 1975). Maximum force was tested twice before insertion of the recording electrode and compared with that obtained when the electrodes had been removed.
Usually these measurements were identical within $5 \%$. Elbow flexion was examined at a force of $30 \%$ of maximum, and the diagnostic yield was compared with that obtained when a force of $10 \%$ and a standard force of $2 \mathrm{~kg}$ were used. To evaluate whether correction for variation in the contribution of forearm flexors increased the diagnostic yield, turns were recorded simultaneously in $\mathrm{m}$. biceps brachii and $\mathrm{m}$. brachioradialis (34 patients). The procedure for correction of the force contributed by the flexors of the forearm has been described (Fuglsang-Frederiksen and Månsson, 1975). Elbow extension was examined at a force of $10 \%$ of maximum and at a standard force of $2 \mathrm{~kg}$.

\section{RESULTS}

ELBOW FLEXION 1. Standard force of $2 \mathrm{~kg}$ compared with force which was fixed fraction of maximum force With a force of $2 \mathrm{~kg}, 12$ of 20 patients had an increased number of turns. In 
four patients, this increase could not be ascribed solely to an increase in the number of motor units activated, or to an increase in the frequency of discharge. The increase in eight patients could be a false positive indication of myopathy. With a force of $30 \%$ of maximum, nine patients were outside the range of controls (Fig. 3) and only in these patients could the increase in turns be attributed to a change in the duration and the shape of individual motor unit potentials. The error implicit in the use of a standard force of $2 \mathrm{~kg}$ could not be avoided by using the ratio of turns to mean amplitude. In normal subjects the ratio was independent of the force for a force of $10-30 \%$ of maximum. When the force was less than $10 \%$ or greater than $30 \%$ the ratio was diminished (unpublished findings). In a third of the normal subjects a force of $2 \mathrm{~kg}$ was less than $10 \%$ of maximum force, while it was from $7 \%$ to $86 \%$ in patients with myopathy.

2. Contribution of forearm flexors and diagnostic yield When there is proximal muscular weakness the relative contribution of forearm flexors to the force increases. When correction was made for variation in the force carried by forearm flexors, 17 of 34 patients were identified as myopathic by an increase in turns, as compared with 14 when no correction was made (force 30\% of maximum). However, this increase in diagnostic yield was not significant.

When the same 15 patients were investigated with a load of $10 \%$ and of $30 \%$ of maximum, the diagnostic yield was the same. The effect of
M. BICEPS BRACHII ( 20 patients)

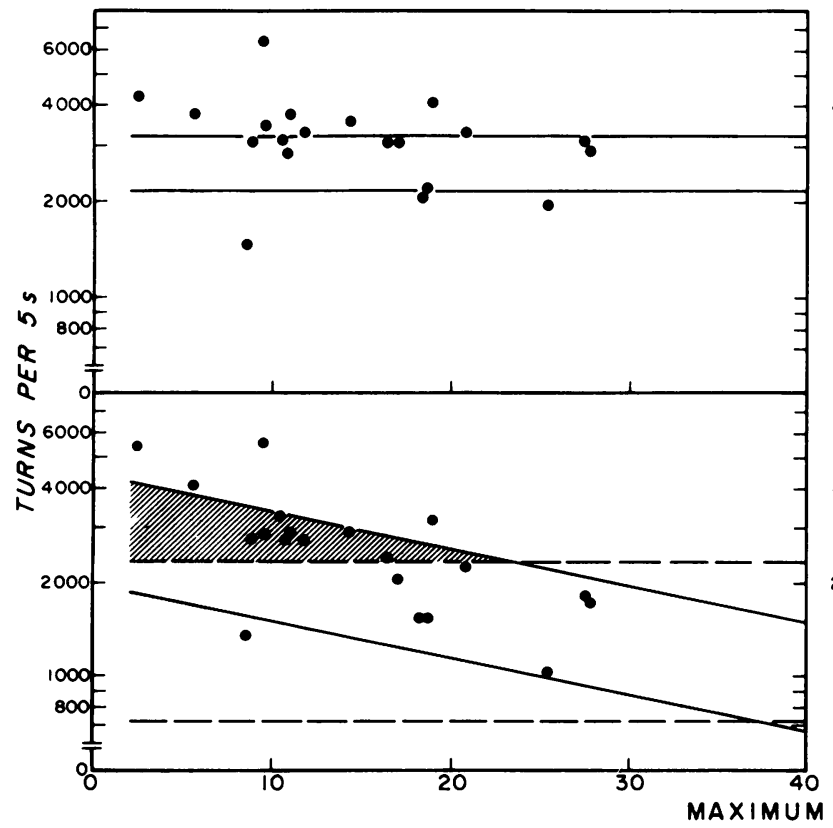

M. TRICEPS BRACHII (10 patients)

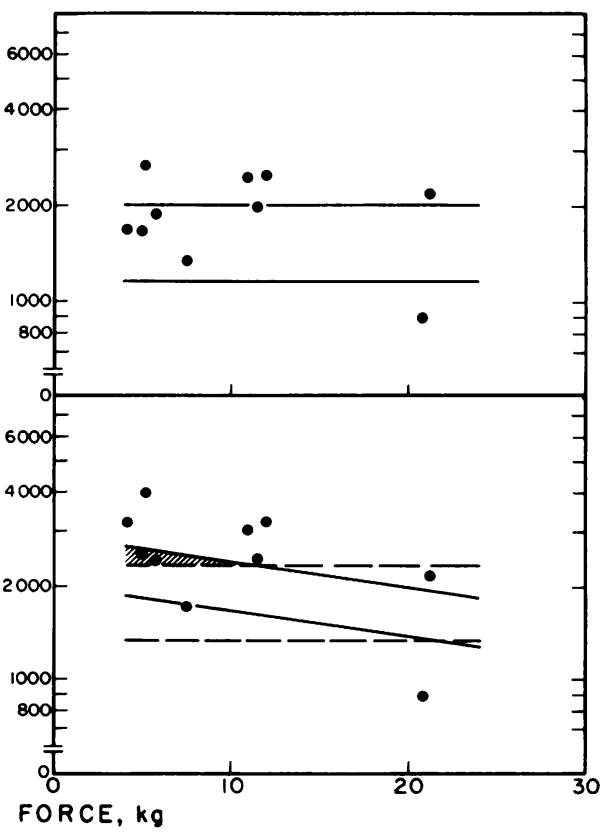

FIG. 3 Number of turns in myopathy (log. scale) as a function of the maximum force. Above: at a force of $30 \%$ ( $\mathrm{m}$. biceps brachii) and $10 \%$ of maximum force ( $\mathrm{m}$. triceps brachii). Full lines: $95 \%$ confidence limits. Below: at a force of $2 \mathrm{~kg}$. Full lines: $95 \%$ confidence limits of the regression line in controls. Dashed lines: $95 \%$ confidence limits of the average in controls (disregarding differences in maximum force). The points within the striped areas indicate false positive increases in the number of turns. (Regression lines: $m$. biceps brachii 15 adults and five children: $\log$. turns $=3.471-0.012$ maximum force, $S D=0.087, P<0.001 ; \mathrm{m}$. triceps brachii 12 adults: log. turns $=3 \cdot 388-0 \cdot 008$ maximum force, $S D=0 \cdot 039, P<0 \cdot 001)$. 
correction for variation in contribution of forearm flexors was also the same at a force of $10 \%$ and $30 \%$ of maximum.

3. Diagnostic yield Pattern of recruitment during $30 \%$ of maximum force In $\mathrm{m}$. biceps brachii the number of turns per five seconds was increased in 15 of 38 patients with myopathy (progressive muscular dystrophy, myotonic dystrophy, and congenital myopathy). The increase in turns was not systematically related to the decrease in maximum force, which was as much as $90 \%$ (Fig. 4). An increase in the incidence of short time intervals identified four patients as myopathic, who did not have an increase in turns and brought the total diagnostic yield to $50 \%$.
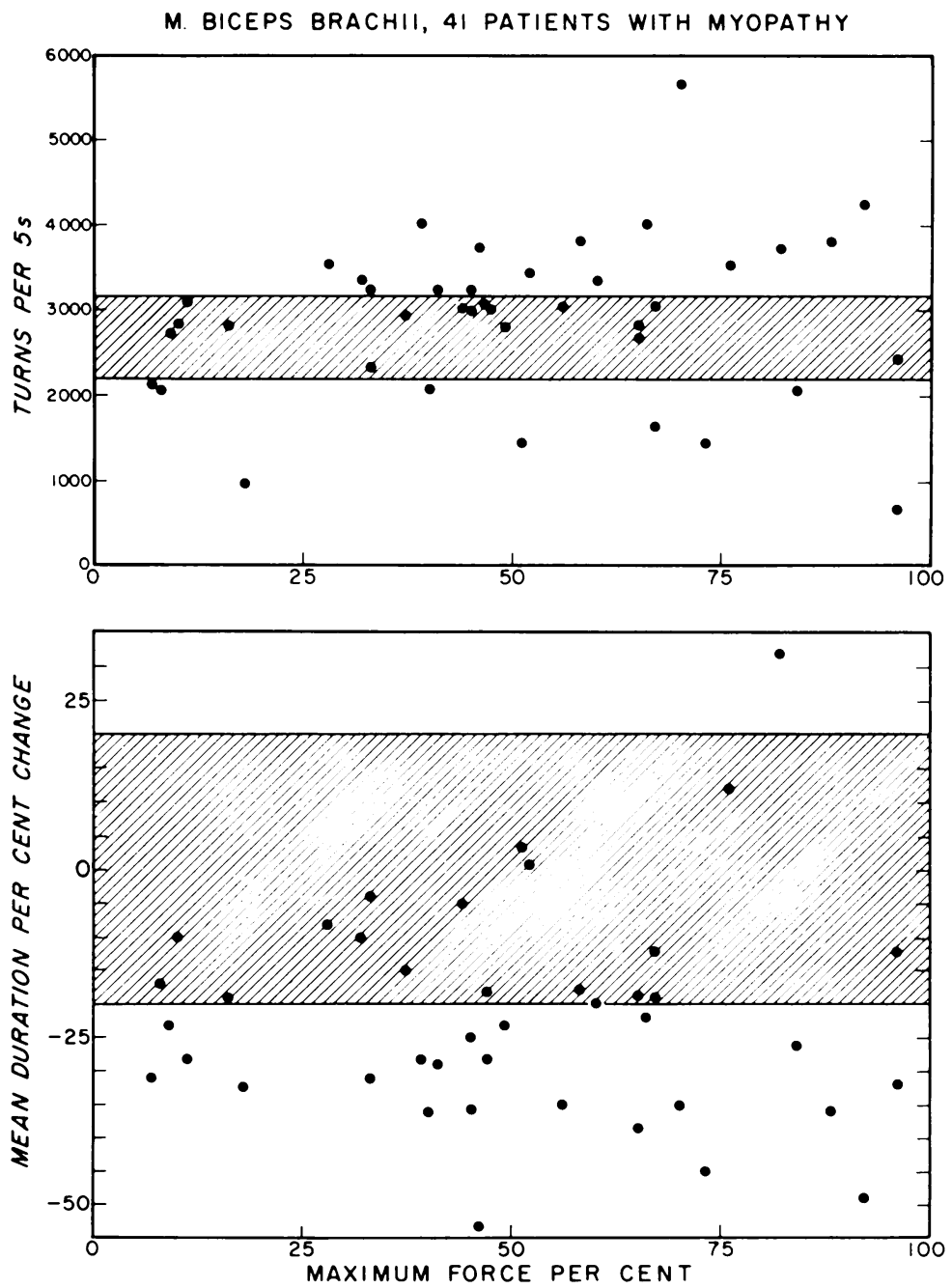

FIG. 4 Turns and mean duration of motor unit potentials as a function of the degree of weakness in patients with myopathy. Ordinate above: number of turns per $5 s$; below: mean duration of motor unit potentials in per cent of the normal average matched for age. Abscissa: decrease in maximum force in per cent of normal. The striped areas indicate the normal range $( \pm 2 S D)$. 
A decreased mean amplitude was present in another nine patients, who had normal (or decreased) turns and a normal incidence of small time intervals. A decrease in amplitude, however, is less specific, because it may occur when weakness is secondary to a lesion of peripheral nerve. An increase in the incidence of low amplitudes between turns did not increase the diagnostic yield because it occurred only in those patients in whom the mean amplitude was diminished. The greatest diagnostic yield was obtained when turns were related to amplitude, the ratio of turns to mean amplitude being increased in $71 \%$ of the patients. The cumulative diagnostic yield obtained with the different criteria was $87 \%$ (Fig. 5).

Nine patients had a decreased number of turns, seen more often in facioscapulohumeral type (six of 12) than in other types of muscular dystrophy (three of 26). Although a decrease in turns is characteristic of a neurogenic lesion (unpublished observations), five of these patients could still be distinguished from a neuropathy because of an increased ratio of turns to mean amplitude.

Individual motor unit potentials during weak effort In $\mathrm{m}$. biceps brachii the mean duration of motor unit potentials was diminished in 22 of 38 patients, equally often among patients with progressive muscular dystrophy, myotonic dystrophy, and congenital myopathy. The decrease in mean duration was unrelated to the decrease in maximum force (Fig. 4). An increased incidence of polyphasic potentials was found in $70 \%$ of the patients, twice as often when the maximum force was diminished as when the force was normal or borderline. The decrease in mean duration combined with the increase in polyphasic potentials added to a diagnostic yield of $89 \%$.

The amplitude of the individual motor unit potentials was within the range of normal ino nearly all patients and did not contribute to the

PATTERN OF ELECTRICAL ACTIVITY DURING MODERATE EFFORT (30\% of maximUm)

Increase in turns per $5 \mathrm{~s}$

Increase in \% time intervals $\leq 0.75 \mathrm{~ms}$

Decrease in mean omplitude

Increose in \% omplitude $\leq 0.5 \mathrm{mV}$

Increase in $\frac{\text { turns }}{\text { mean omplitude }}$

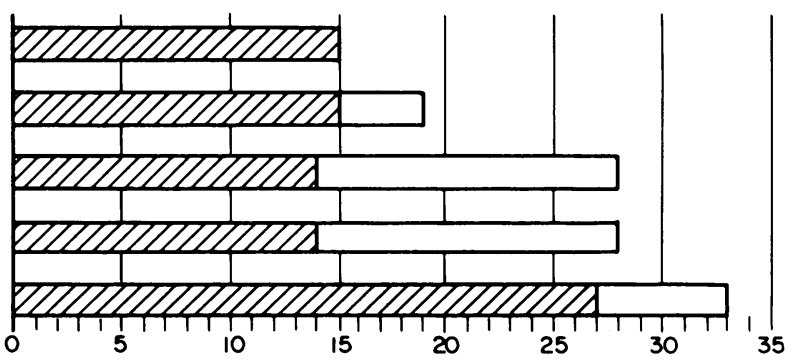

INDIVIDUAL MOTOR UNIT POTENTIALS RECORDED DURING WEAK EFFORT

Decreased durotion of motor unit pot.

Increosed incidence of polyphasic pot.

Decreased ompl. during full effort

Decreosed ampl. of motor unit potentials al

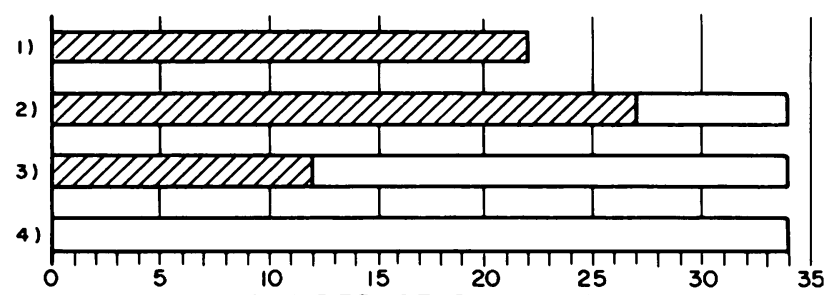

$\begin{array}{lll}\text { 1) } \geq 20 \% \text { of normal } & 3 \text { ) }<2 \mathrm{mV}\end{array}$

NUMBER OF PATIENTS

2) $>12 \%$

4) $>40 \%$ of normal

FIG. 5 Brachial biceps: 38 patients with muscular dystrophy. Cumulative diagnostic yield (from above to below) obtained from the different parameters of the analysis of the pattern of electrical activity during moderate effort and from the properties of the indiviual motor unit potentials. The hatched areas indicate the diagnostic yield of each parameter. 
diagnostic yield. A decreased amplitude of the recruitment pattern during full effort was found in 12 patients (Fig. 5).

Comparison of diagnostic yield during moderate and weak effort In 10 patients, in whom the ratio of turns to mean amplitude was increased, the mean duration of motor unit potentials was normal. Conversely, in five patients in whom the ratio of turns to mean amplitude was normal, the mean duration was diminished. Thus, both with the ratio of turns to mean amplitude and the mean duration of motor unit potentials as criteria of abnormality, 32 patients were identified as myopathic. Using all criteria of both procedures all patients, except one, were identified as myopathic.

Patients with polymyositis Three patients with polymyositis were identified as myopathic by the increased ratio of turns to mean amplitude and by the decreased mean duration of motor unit potentials.

ELBOW EXTENSION The diagnostic yield obtained with the study of $\mathrm{m}$. triceps brachii was similar to that found in the $\mathrm{m}$. biceps brachii. Turns were increased in four of 10 patients and the ratio of turns to mean amplitude was increased in five patients. The mean duration of motor unit potentials was diminished in five patients. One patient with normal duration had an increased incidence of polyphasic potentials. In two patients, in whom the ratio of turns to mean amplitude was increased, the mean duration of motor unit potentials was normal, and, conversely, in two patients in whom the ratio of turns to mean amplitude was normal, the mean duration was diminished. Using all criteria of both procedures, all patients, except one, were identified as myopathic.

\section{DISCUSSION}

Eighty-seven per cent of patients with myopathy showed abnormalities in the pattern of recruitment of electrical activity which must be attributed to changes in the shape and the duration of the individual motor unit potentials. The parameter which was changed most often was the ratio of turns to amplitude between turns at a force of $30 \%$ of maximum. Adjustment of the force to a fixed fraction of maximum avoided the false positive findings invariably associated with the use of a standard force of $2 \mathrm{~kg}$.

For the group of patients as a whole, the diagnostic yield obtained with $30 \%$ of maximum force was the same as that obtained from the analysis of the individual motor unit potentials. However, in some patients only those motor units were involved which were recruited during strong or during weak effort.

The increased ratio of turns to mean amplitude seemed to be the criterion with the best diagnostic yield. The ratio was increased, even in some of those patients who had normal or decreased turns; when turns were too low the patient did not exert maximum force or fibre loss was so severe that motor units were lost in toto. This is in agreement with the fact that the ratio of turns to mean amplitude was constant in normal subjects when the force was $10-30 \%$ of maximum.

Correction of turns for the force exerted by forearm flexors did not increase the diagnostic yield, although $\mathrm{m}$. biceps brachii was often more severely involved than $\mathrm{m}$. brachioradialis. On the other hand, in normal subjects, the relative contribution of the brachioradialis to the force was the same, above $20 \%$ of maximum, as indicated by the same relative increase in turns in $\mathrm{m}$. biceps brachii and $\mathrm{m}$. brachioradialis, when the force was increased $20 \%-30 \%$ of maximum (unpublished findings).

If this applies to patients with myopathy, the number of turns in the brachial biceps is not affected by the contribution of $\mathrm{m}$. brachioradialis.

\section{SUMMARY}

In 41 patients with myopathy the ratio of the number of turns per $5 \mathrm{~s}$ to mean amplitude between turns during moderate effort $30 \%$ of maximum) gave a diagnostic yield of $70 \%$. The total diagnostic yield increased to $87 \%$ when abnormalities in the number of turns per $5 \mathrm{~s}$, the incidence of short time intervals between turns, and the mean amplitude were included. In the same muscles the decrease in mean duration of motor unit potentials identified $60 \%$ of the patients as myopathic. The diagnostic yield was increased to $89 \%$ if an increased incidence of 
polyphasic potentials was included in the evaluation. In 10 patients the ratio of turns to mean amplitude recorded during moderate effort was increased, whereas the mean duration of motor unit potentials was normal. Conversely, in five patients the mean duration of motor unit potentials was diminished and the ratio of the number of turns to mean amplitude was normal. When a standard force of $2 \mathrm{~kg}$ was used it could often not be decided whether an increase in turns was due to specific changes in motor unit parameters or to an increase in the number of motor units recruited in a weak muscle. This uncertainty was avoided when the force was a fixed fraction of maximum.

The work was supported by a grant from The Muscular Dystrophy Associations of America, New York. We are indebted to Dr P. Rosenfalck, Copenhagen, and Dr R. G. Willison, London, for helpful suggestions in the preparation of the manuscript.

\section{REFERENCES}

Buchthal, F. (1957). An Introduction to Electromyography, pp. 43. Gyldendal: Copenhagen.

Dowling, M. H., Fitch, P., and Willison, R. G. (1968). A special purpose digital computer (Biomac 500) used in the analysis of the human electromyogram. Electroencephalography and Clinical Neurophysiology, 25, 570-573.

Fitch, P. (1967). An analyser for use in human electromyography. Electronic Engineering, 39, 240-243.

Fuglsang-Frederiksen, A., and Månsson, A. (1975). Analysis of electrical activity of normal muscle in man at different degrees of voluntary effort. Journal of Neurology, Neurosurgery, and Psychiatry, 38, 683-694.

Rose, A. L., and Willison, R. G. (1967). Quantitative electromyography using automatic analysis: studies in healthy subjects and patients with primary muscle disease. Journal of Neurology, Neurosurgery, and Psychiatry, 30, 403-410.

Smyth, D. P., and Willison, R. G. (1975). The application of quantitative EMG to paediatrics. Proceedings of the $V$. International Congress of Electromyography, p. 63. Rochester, Minnesota.

Willison, R. G. (1964). Analysis of electrical activity in healthy and dystrophic muscle in man. Journal of Neurology, Neurosurgery, and Psychiatry, 27, 386-394. 